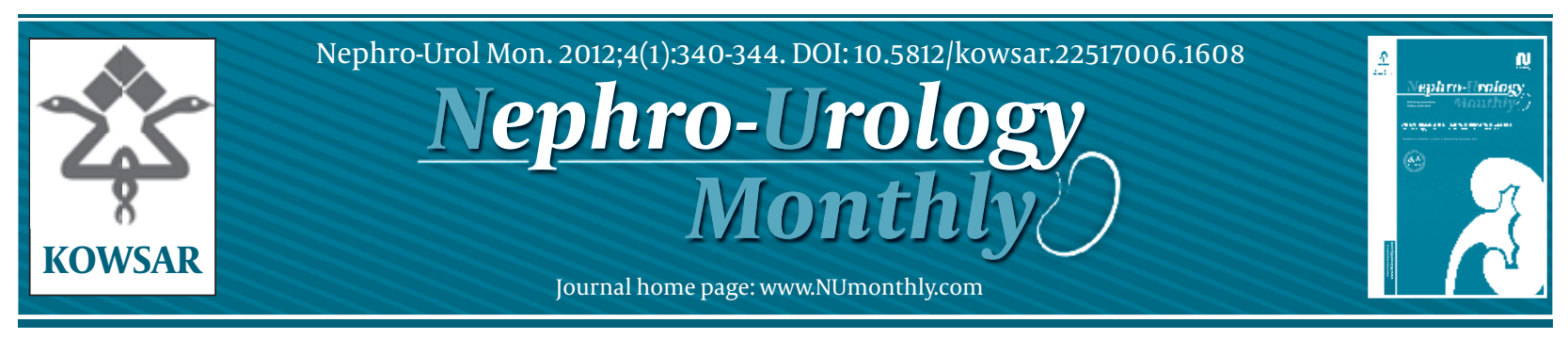

\title{
Challenges in Diagnosis and Treatment of Acute Kidney Injury During Pregnancy
}

\author{
Abdulkareem O. Alsuwaida ${ }^{*}$ \\ ${ }^{1}$ Department of Medicine, King Saud University, Riyadh, Saudi Arabia
}

\begin{tabular}{|c|c|}
\hline A R R T I I C L L E I I N F O & A B S T R A C T \\
\hline Article type: & \multirow{9}{*}{$\begin{array}{l}\text { Pregnant women with acute kidney injury (AKI) represent a unique challenge for health } \\
\text { care providers. In approaching AKI in pregnant women, emphasis should be placed on } \\
\text { making an early and accurate diagnosis to allow prompt intervention and to facilitate } \\
\text { recovery from AKI. In this article, I review the prevalence of AKI in pregnancy and the } \\
\text { impact it has on morbidity and mortality. I then review diagnostic criteria and discuss } \\
\text { fetal monitoring methods. The utility of various renal replacement methods available } \\
\text { for pregnant women with AKI is discussed, as well as the specific adjustments to hemo- } \\
\text { dialysis prescriptions for pregnant women. This review summarizes the existing data on } \\
\text { the management of AKI during pregnancy, however, most of these studies were observa- } \\
\text { tional. Future research with longitudinal study designs are needed to allow examination } \\
\text { of the effect of AKI during pregnancy on adverse maternal and fetal outcomes. }\end{array}$} \\
\hline Review Article & \\
\hline Article history: & \\
\hline Received: 13 Jun 2011 & \\
\hline Revised: 09 Jul 2011 & \\
\hline Accepted: 19 Jul 2011 & \\
\hline & \\
\hline egnanc & \\
\hline Acute Kidney Injury & \\
\hline
\end{tabular}
Renal Replacement Therapy Renal Dialysis

Copyright $\odot 2012$, Kowsar M.P.Co. All rights reserved.

- Implication for health policy/practice/research/medical education:

This review summarizes the existing data on the management of AKI during pregnancy, however, most of these studies were observational. Future research with longitudinal study designs are needed to allow examination of the effect of AKI during pregnancy on adverse maternal and fetal outcomes.

Please cite this paper as:

Alsuwaida AO. Challenges in Diagnosis and Treatment of Acute Kidney Injury During Pregnancy. Nephro-Urol Mon. 2012.4(1):340-44. DOI: $10.5812 /$ kowsar.22517006.1608

\section{Introduction}

An acute kidney injury (AKI) in pregnant patients poses unique challenges for clinicians involved in the care of these patients. The renal system undergoes anatomical and physiological changes during a normal pregnancy. Clinicians need to be familiar with these changes because they may affect the diagnosis and management of AKI. Renal plasma flow increases by $50 \%$ to $70 \%$ during pregnancy in the first 2 trimesters (1). Additionally, the glomerular filtration rate (GFR) increases from an average of $97 \mathrm{~mL}$ / min to $128 \mathrm{~mL} / \mathrm{mm}$ by the end of the first trimester. Consequently, both blood urea nitrogen (BUN) and creatinine concentrations are lower than the normal range, and thus

* Corresponding author: Abdulkareem O. Alsuwaida, Department of Medicine, King Saud University, P.O. Box 2925 Riyadh 11321, Riyadh, Saudi Arabia.Tel:+966-14672398, Fax:+966-14671034,E-mail: suwaida@ksu.edu.sa

DOI:10.5812/kowsar.22517006.1608

Copyright $\odot 2012$, Kowsar M.P.Co. All rights reserved. a normal BUN or creatinine level in a pregnant female may actually indicate underlying renal disease (2). Serum sodium decreases by $3 \mathrm{mEq} / \mathrm{L}$ and both ionized and unionized calcium concentrations also show a small decrease (3). Magnesium concentrations decrease by approximately $10 \%$ to $20 \%$ during the first trimester (4). Hyperventilation that occurs during pregnancy is probably due, in part, to progesterone stimulating the respiratory center (5). The effect is chronic respiratory alkalosis, which is compensated for by the renal excretion of bicarbonate. A typical plasma bicarbonate level is $21 \mathrm{mmol} / \mathrm{L}$ (6).

The presence of AKI increases the mortality associated with any primary disease (7). The overall mortality rate associated with AKI is $20 \%$, and those requiring renal replacement therapy (RRT) have a mortality rate approaching $50 \%$. It has traditionally been thought that patients who do survive ultimately recover renal function; however, recent population-based studies suggest that a strikingly large percentage of patients who have AKI require perma- 
nent RRT or do not fully recover renal function $(8,9)$.

\section{Epidemiology of AKI in Pregnancy}

AKI is a common medical problem, affecting approximately $5 \%$ of all hospitalized patients and $30 \%$ of critically ill patients (10-12). However, the incidence of AKI in pregnancy is not as common, decreasing from 1 per 2000 pregnancies to 1 in 20,000 pregnancies in developed countries $(13,14)$. This low incidence is probably attributed to improved obstetric care. Conversely, the incidence is higher and continues to be a major problem in developing countries, resulting in high maternal mortality (15).

\section{Etiology of AKI in Pregnancy}

The initial assessment of patients with AKI classically includes the differentiation among prerenal, intrinsic renal, and postrenal causes when the patient is in a nonpregnant state (16-19). However, certain conditions are associated with pregnancy that varies between the first and second halves of gestation. In most women, careful clinical assessment will identify the underlying etiology (Table 1, Algorithm 1). In early pregnancy, the most common problems are prerenal disease, due to hyperemesis gravidarum, or acute tubular necrosis, resulting from a septic abortion (20).

Pre-eclampsia and HELLP (hemolysis, elevated liver enzymes, and low platelet count) are some of the most important causes of AKI in pregnancy, but most of the patients suffering from any of these conditions do not have AKI (21-23). The estimated incidence of AKI occurring with pre-eclampsia is $1.5 \%$ to $2 \%(21)$. Other pregnancy-specific causes include acute fatty liver of pregnancy, thrombotic thrombocytopenic purpura, hemolytic uremic syndrome, amniotic fluid embolism, infection, sepsis, intravascular volume depletion and obstruction, or idiopathic etiologies (21-23). At the end of pregnancy, uterine hemorrhage and hypotension occur in 7\% to 39\% of patients with AKI (21-24). Postpartum hemorrhage is one of the leading causes of maternal death (23-25). Bilateral renal cortical necrosis (in less severe cases acute tubular necrosis) may be induced during pregnancy by abruptio placentae or other severe complications such as placenta previa, prolonged intrauterine fetal death, or amniotic fluid embolism $(26,27)$.

\section{Diagnosis of AKI in Pregnancy}

Acute kidney injury is defined as an abrupt absolute increment in the serum creatinine concentration of $\geq$ $0.3 \mathrm{mg} / \mathrm{dL}(26.4 \mu \mathrm{mol} / \mathrm{L})$ from the baseline concentration within 48 hours, a percentage increase in the serum creatinine concentration of $\geq 50 \%$, or oliguria of less than $0.5 \mathrm{~mL} / \mathrm{kg}$ per hour for more than 6 hours $(10,11)$. The absolute change in serum creatinine of $\geq 0.3 \mathrm{mg} / \mathrm{dL}$ is based on epidemiologic data that demonstrated an $80 \%$ increase in mortality risk associated with changes in the serum creatinine concentration of only 0.3 to $0.5 \mathrm{mg} / \mathrm{dL}$ $(10,11,17)$. However, the clinical utility of these criteria during pregnancy still needs to be assessed. The utility of the creatinine increment cutoff of $0.3 \mathrm{mg} / \mathrm{dL}$ may need to be studied to determine its applicability in testing for AKI in pregnant women, although the urine output criterion will continue to be the most reliable criterion for early diagnosis. Therefore, clinicians should have a low threshold for triggering laboratory assessment for AKI once a drop in urine output is observed in a pregnant woman. Fractional excretion of sodium and fractional excretion of urea nitrogen have been used to distinguish between the two main causes of AKI: prerenal state and acute tubular necrosis (28). However, these formulas have not been validated in pregnancy. Several biomarkers for AKI have been evaluated in nonpregnant patients; however, none of the biomarkers have been used for daily practice. These biomarkers will hopefully facilitate early diagnosis and stratify the cases of AKI $(28,29)$.

\begin{tabular}{lll}
\hline \multicolumn{2}{l}{ Table 1. Pregnancy-Related Causes of Acute Kidney Injury } & \\
\hline Prerenal & Renal & Postrenal \\
\hline Hypovolemia & Acute tubular necrosis & Gravid uterus \\
Vomiting & Acute interstitial nephritis & Papillary necrosis \\
Hyperemesis gravidarum & Acute fatty liver & Polyhydramnios \\
Blood loss & Pre-eclampsi & \\
Abortion & HELLP a syndrome & \\
Placenta previa & TTP or HUS a & \\
Placenta abruption & Acute cortical necrosis & \\
Hypoperfusion & Glomerulonephritis & \\
Sepsis & Amniotic fluid embolism & \\
Pyelonephritis & Antiphospholipid syndrome & \\
Infected abortion & Arterial thrombosis & \\
Heart failure & Renal vein thrombosis & \\
\hline
\end{tabular}

a Abbreviations: HELLP, hemolysis elevated liver enzymes and a low platelet count; HUS, hemolytic uremic syndrome; TTP, thrombotic thrombocytopenic purpura 


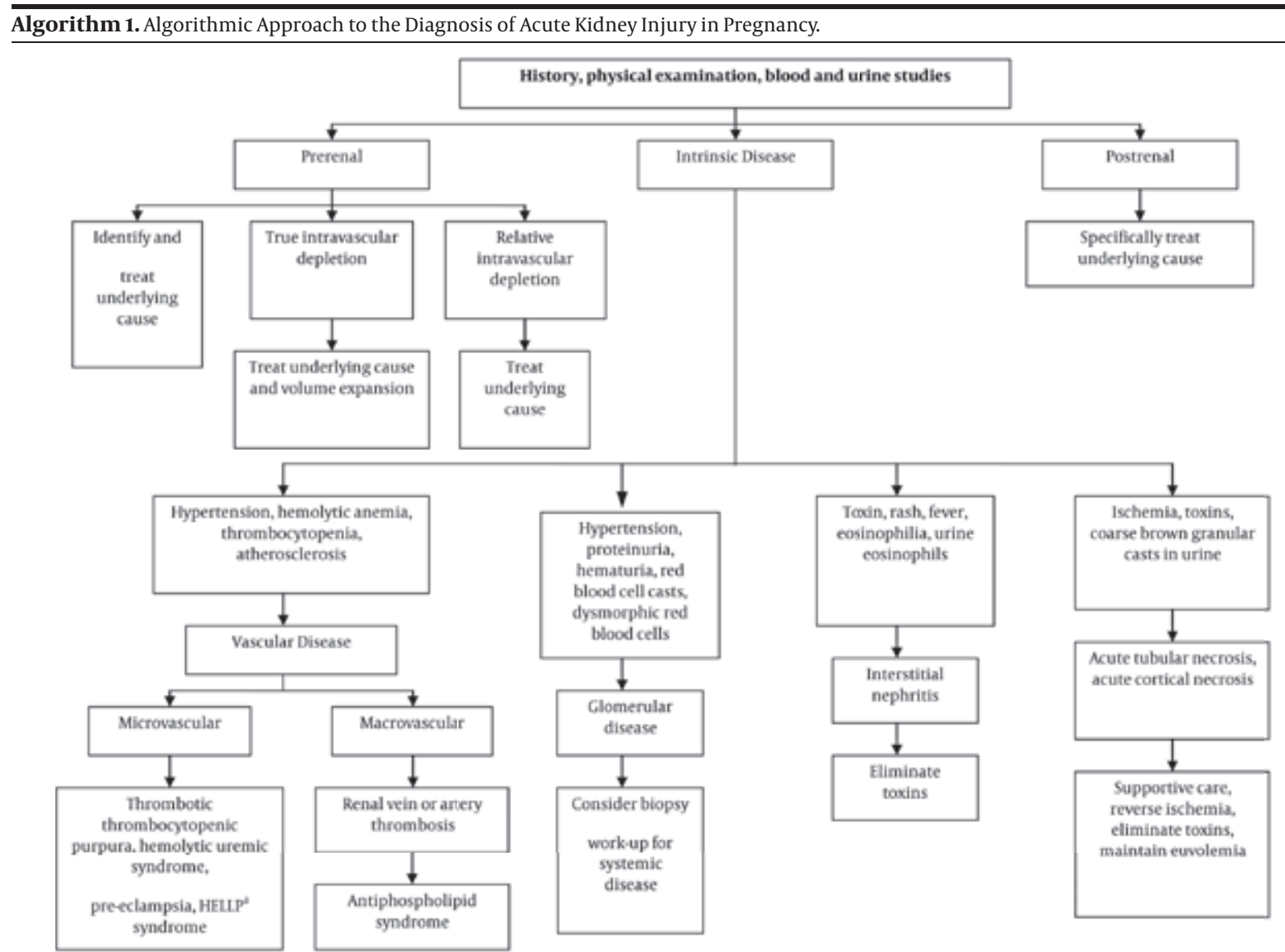

\footnotetext{
a Abbreviation: HELLP, hemolysis elevated liver enzymes and a low platelet count
}

\section{Management of AKI in Pregnancy}

The optimal care of pregnant women with AKI requires a multidisciplinary team, including a maternal-fetal medicine specialist, who should be involved early in the care (Algorithm 2). Early treatment for AKI typically includes optimization of the hemodynamic status and correction of any volume deficit. This will have a salutary effect on kidney function, helping to minimize progression of further kidney injury, and potentially facilitating recovery from AKI with a minimization of any residual chronic impairment of kidney function (30). The intravascular volume and mean arterial pressure should be maintained, and acidosis and electrolyte abnormalities should be corrected. Further damage should be prevented by avoiding nephrotoxic agents. All medications need to be adjusted for the level of renal function. Pregnant women with AKI need to be monitored for any other organ dysfunction.

Fetal monitoring is needed for all pregnant women with AKI. In cases where the gestational age is 25 weeks or less, assessment is usually limited to Doppler auscultation to document the fetal heart $(31,32)$. At 26 weeks or more, other more sensitive methods can be used, including a fetal movement assessment, contraction stress test, nonstress test, biophysical profile, or umbilical artery Doppler velocimetry $(31,32)$. Regular fetal monitoring with contingency planning for a possible emergency cesarean delivery is conducted if fetal distress is observed for fetuses that have reached an adequate level of maturity.

No controlled trial data are available, but clinicians should be prepared to start dialysis early in pregnant patients and maintain effective doses as the pregnancy continues (33). Acute indications for dialysis are the same for pregnant patients as for nonpregnant patients in terms of fluids, electrolytes, and complications of uremia. However, the replacement therapy should be initiated early and not postponed until the onset of advanced uremic manifestations $(33,34)$. Information from registries suggests that aggressive control of azotemia results in better fetal and maternal outcomes; therefore, we should target a BUN within the normal range $(33,34)$.

The options for renal replacement therapy in patients with AKI include peritoneal dialysis (PD), intermittent hemodialysis, and continuous renal replacement therapy (CRRT). PD is less efficient than hemodialysis in providing adequate clearance in an acute state, and it is more difficult to insert a PD catheter (35). The gravid uterus will also limit the volume of fluid used in each exchange (36). Despite these limitations, this treatment may be the only option available in many rural areas in developing countries. Adequate control of azotemia with a lower 


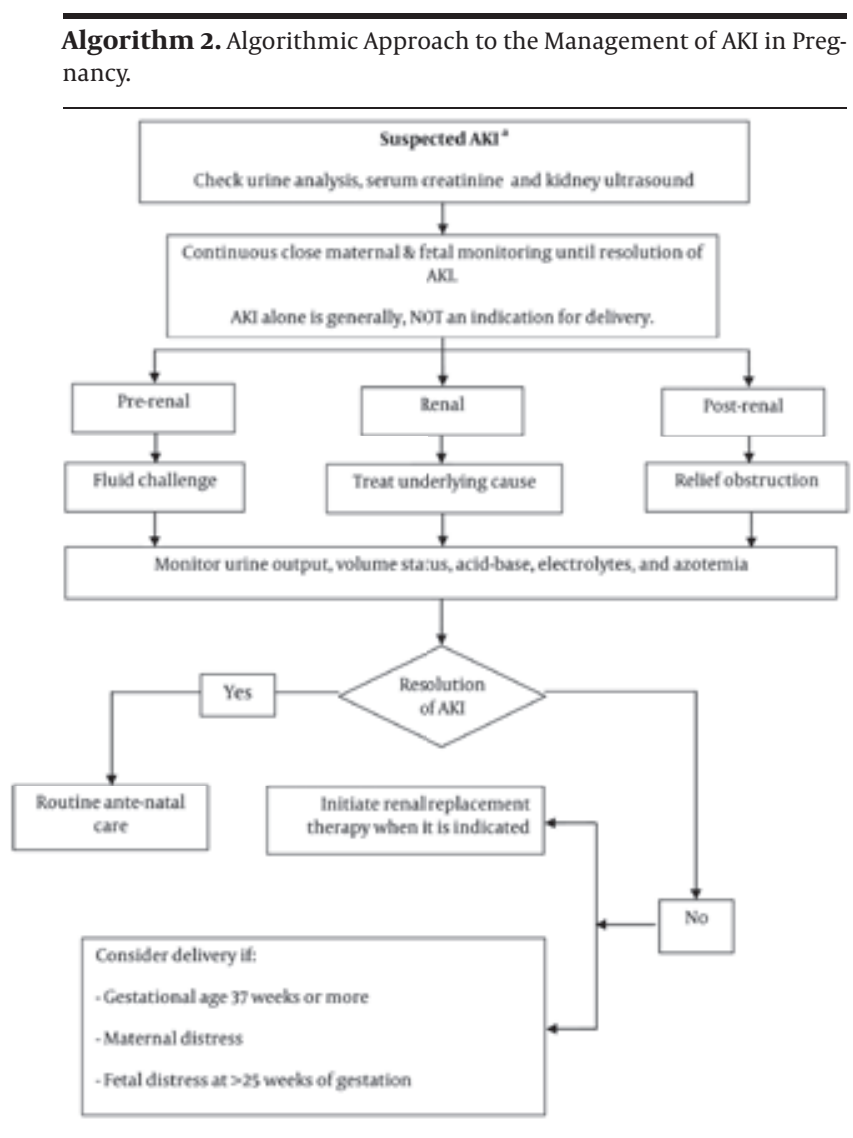

$\bar{a}$ Abbreviations: AKI, acute kidney injury; HELLP, hemolysis elevated liver enzymes and a low platelet count; HUS, hemolytic uremic syndrome, TTP, thrombotic thrombocytopenic purpura

blood flow rate to avoid hemodynamic instability can be performed by either slower solute removal (over 6 to 12 hours by sustained low-efficiency dialysis) or by CRRT. Before acute hemodialysis is initiated, vascular access must be established. Placement of the venous dialysis catheter must be considered carefully, particularly in critically ill pregnant women. The location depends upon whether the patient has a clinical and ambulatory status (37). The internal jugular vein is most often the preferred site. The femoral vein is another site that is used but is less preferred because of the increased risk of deep vein thrombosis during pregnancy.

Determining the ultrafiltration (5) goals in pregnant women can be challenging. The intravascular volume in a normal pregnancy is expanded; therefore, a guided UF that avoids intradialytic hypotension is critical. Monitoring uteroplacental perfusion, fetal blood flow, and amniotic fluid volume may assist in maintaining adequate fetal perfusion and titrating ultrafiltration $(38,39)$. This ultrafiltration can be achieved by minimizing the UF rate requirements by increasing the frequency and duration of treatments, as well as by ultrafiltration profiling. Vasoconstriction due to a lower body temperature has been used to increase vascular resistance and improve hemodynamic stability during dialysis. Hypothermia, however, may be an undesirable consequence in critically ill pregnant patients due to the adverse effects of vasocon- striction and possible decline in uterine perfusion (40). Similarly, sodium profiling should be avoided because the serum sodium concentration in pregnant women is physiologically decreased, and the impact of sodium profiling on a fetus is not known. The dialysate calcium and potassium concentration should be adjusted to avoid electrolyte disturbances.

Coagulation factors are also altered during pregnancy. Fibrinogen (factor I) is markedly increased by approximately $2 \mathrm{~g} / \mathrm{L}$ at term (41). Factors VII, VIII, and X are also increased. Furthermore, the activity of factors IX and XII increase, and factors XI and XIII decrease by $30 \%$ or more at term $(42,43)$. Antithrombin II probably decreases (43). A progressive increase occurs in fibrin and fibrinogen degradation products throughout pregnancy. The agent of choice is heparin because it does not cross the placental barrier, has no teratogenicity, and is easy to dose $(44,45)$. Heparinization of the extracorporeal circuit (regional heparinization) with the use of its protamine sulfate is another method that is recommended to correct the excess anticoagulant effect of heparin, particularly in women with active bleeding (46). Trisodium citrate safety in pregnancy is not known; therefore, its use should be avoided. The dialysate bicarbonate concentration should vary based upon the acid-base status of the patient; however, overcorrection should be avoided, and the physiologic metabolic acidosis should be targeted. For postpartum patients, no evidence exists regarding dosing dialysis any differently to that for other patients with AKI.

\section{Conclusion}

AKI during pregnancy poses a challenge for physicians. In view of the multifaceted problems that potentially complicate pregnancies in women with AKI, multidisciplinary involvement comprising nephrologists, obstetricians, and neonatologists is extremely important. To date, there have been no randomized or prospective trials that have examined the impact of AKI on maternal and fetal outcome or therapeutic interventions. Therefore, epidemiologic studies are a crucial first step in achieving early detection and intervention, as well as for improving outcomes in pregnant women with AKI.

\section{Acknowledgments}

We thank Mrs. Aileen Esteibar for her secretarial assistance.

\section{Financial Disclosure}

None of the authors declared a conflict of interest.

\section{Funding/Support}

There is no funding to be acknowledged.

\section{References}

1. Koetje PM, Spaan JJ, Kooman JP, Spaanderman ME, Peeters LL. 
Pregnancy reduces the accuracy of the estimated glomerular filtration rate based on Cockroft-Gault and MDRD formulas. Reprod Sci. 2011;18(5):456-62.

2. Dunlop W, Davison JM. Renal haemodynamics and tubular function in human pregnancy. Baillieres Clin Obstet Gynaecol. 1987;1(4):769-87.

3. Lindheimer MD, Davison JM. Osmoregulation, the secretion of arginine vasopressin and its metabolism during pregnancy. Eur JEndocrinol.1995;132(2):133-43.

4. Kurzel RB. Serum magnesium levels in pregnancy and preterm labor. Am J Perinatol. 1991;8(2):119-27.

5. Jensen D, Duffin J, Lam YM, Webb KA, Simpson JA, Davies GA, et al. Physiological mechanisms of hyperventilation during human pregnancy. Respir Physiol Neurobiol. 2008;161(1):76-86.

6. Lim VS, Katz AI, Lindheimer MD. Acid-base regulation in pregnancy. Am J Physiol. 1976;231(6):1764-9.

7. Murugan R, Kellum JA. Acute kidney injury: what's the prognosis? Nat Rev Nephrol. 2011;7(4):209-17.

8. Metnitz PG, Krenn CG, Steltzer H, Lang T, Ploder J, Lenz K, et al. Effect of acute renal failure requiring renal replacement therapy on outcome in critically ill patients. Crit Care Med. 2002;30(9):2051-8.

9. Hsu CY. Linking the population epidemiology of acute renal failure, chronic kidney disease and end-stage renal disease. Curr Opin Nephrol Hypertens. 2007;16(3):221-6.

10. Lameire N, Van Biesen W, Vanholder R. Acute renal failure. Lancet. 2005;365(9457):417-30.

11. Mehta RL, Kellum JA, Shah SV, Molitoris BA, Ronco C, Warnock DG, et al. Acute Kidney Injury Network: report of an initiative to improve outcomes in acute kidney injury. Crit Care. 2007;11(2):R31.

12. Chertow GM, Burdick E, Honour M, Bonventre JV, Bates DW. Acute kidney injury, mortality, length of stay, and costs in hospitalized patients. J Am Soc Nephrol. 2005;16(11):3365-70.

13. Ventura JE, Villa M, Mizraji R, Ferreiros R. Acute renal failure in pregnancy. Ren Fail. 1997;19(2):217-20.

14. Hou S, Peano C. Acute renal failure in pregnancy. Saudi J Kidney Dis Transpl.1998;9(3):261-6.

15. Selcuk NY, Tonbul HZ, San A, Odabas AR. Changes in frequency and etiology of acute renal failure in pregnancy (1980-1997). Ren Fail. 1998;20(3):513-7.

16. Cruz DN, Bagshaw SM, Ronco C, Ricci Z. Acute kidney injury: classification and staging. Contrib Nephrol. 2010;164:24-32.

17. Schrier RW, Wang W, Poole B, Mitra A. Acute renal failure: definitions, diagnosis, pathogenesis, and therapy. I Clin Invest. 2004;114(1):5-14

18. Needham E. Management of acute renal failure. Am Fam Physician. 2005;72(9):1739-46.

19. Thadhani R, Pascual M, Bonventre JV. Acute renal failure. N EnglJ Med.1996;334(22):1448-60.

20. Najar MS, Shah AR, Wani IA, Reshi AR, Banday KA, Bhat MA, et al. Pregnancy related acute kidney injury: A single center experience from the Kashmir Valley. Indian J Nephrol. 2008;18(4):159-61.

21. Gammill HS, Jeyabalan A. Acute renal failure in pregnancy. Crit Care Med. 2005;33(10 Suppl):S372-84.

22. Koroshi A, Babameto A. Acute renal failure during acute fatty liver of pregnancy. Nephrol Dial Transplant. 2002;17(6):1110-2.

23. Prakash J, Niwas SS, Parekh A, Pandey LK, Sharatchandra L, Arora $\mathrm{P}$, et al. Acute kidney injury in late pregnancy in developing countries. Ren Fail. 2010;32(3):309-13.

24. World Health Organization. WHO recommendations for the prevention of postpartum haemorrhage. Geneva: World Health Organization. 2007:1808-13.

25. Prakash J, Kumar H, Sinha DK, Kedalaya PG, Pandey LK, Srivastava $\mathrm{PK}$, et al. Acute renal failure in pregnancy in a developing country: twenty years of experience. Ren Fail. 2006;28(4):309-13.
26. Ansari MR, Laghari MS, Solangi KB. Acute renal failure in pregnancy: one year observational study at Liaquat University Hospital, Hyderabad. J Pak Med Assoc. 2008;58(2):61-4.

27. Prakash J, Vohra R, Wani IA, Murthy AS, Srivastva PK, Tripathi K, et al. Decreasing incidence of renal cortical necrosis in patients with acute renal failure in developing countries: a single-centre experience of 22 years from Eastern India. Nephrol Dial Transplant. 2007;22(4):1213-7.

28. Parikh CR, Devarajan P. New biomarkers of acute kidney injury. Crit Care Med. 2008;36(4 Suppl):S159-65.

29. Mcllroy DR, Wagener G, Lee HT. Biomarkers of acute kidney in jury: an evolving domain. Anesthesiology. 2010;112(4):998-1004.

30. Karvellas CJ, Farhat MR, Sajjad I, Mogensen SS, Leung AA, Wald R, et al. A comparison of early versus late initiation of renal replacement therapy in critically ill patients with acute kidney injury: a systematic review and meta-analysis. Crit Care. 2011;15(1):R72.

31. ACOG Practice Bulletin. Clinical Management Guidelines for Obstetrician-Gynecologists, Number 70, December 2005 (Replaces Practice Bulletin Number 62, May 2005). Intrapartum fetal heart rate monitoring. Obstet Gynecol. 2005;106(6):1453-60.

32. ACOG practice bulletin. Antepartum fetal surveillance. Number 9, October 1999 (replaces Technical Bulletin Number 188, January 1994). Clinical management guidelines for obstetrician-gynecologists. Int J Gynaecol Obstet. 2000;68(2):175-85.

33. Okundaye I, Abrinko P, Hou S. Registry of pregnancy in dialysis patients. Am J Kidney Dis. 1998;31(5):766-73.

34. Malik GH, Al-Harbi A, Al-Mohaya S, Dohaimi H, Kechrid M, Shetaia MS, et al. Pregnancy in patients on dialysis-experience at a referral center. J Assoc Physicians India. 2005;53:937-41.

35. Davenport A. Peritoneal dialysis in acute kidney injury. Perit Dial Int. 2008;28(4):423-4; author reply 4-5.

36. Briones-Garduno JC, Diaz de Leon-Ponce MA, Rodriguez-Roldan M, Briones-Vega CG, Torres-Perez J. [Peritoneal dialysis in obstetric patients]. Cir Cir. 2006;74(1):15-20.

37. Oliver MJ, Edwards LJ, Treleaven DJ, Lambert K, Margetts PJ. Randomized study of temporary hemodialysis catheters. Int J Artif Organs. 2002;25(1):40-4.

38. Flack NJ, Sepulveda W, Bower S, Fisk NM. Acute maternal hydration in third-trimester oligohydramnios: effects on amniotic fluid volume, uteroplacental perfusion, and fetal blood flow and urine output. Am J Obstet Gynecol. 1995;173(4):1186-91.

39. Bamberg C, Diekmann F, Haase M, Budde K, Hocher B, Halle H, et al. Pregnancy on intensified hemodialysis: fetal surveillance and perinatal outcome. Fetal Diagn Ther. 2007;22(4):289-93.

40. Jost CM, Agarwal R, Khair-el-Din T, Grayburn PA, Victor RG Henrich WL. Effects of cooler temperature dialysate on hemodynamic stability in "problem" dialysis patients. Kidney Int 1993;44(3):606-12.

41. Manten GT, Franx A, Sikkema JM, Hameeteman TM, Visser GH, de Groot PG, et al. Fibrinogen and high molecular weight fibrinogen during and after normal pregnancy. Thromb Res. 2004;114(1):19-23.

42. Bremme KA. Haemostatic changes in pregnancy. Best Pract Res Clin Haematol. 2003;16(2):153-68.

43. Thornton P, Douglas J. Coagulation in pregnancy. Best Pract Res Clin Obstet Gynaecol. 2010;24(3):339-52.

44. James KV, Lohr JM, Deshmukh RM, Cranley JJ. Venous thrombotic complications of pregnancy. Cardiovasc Surg. 1996;4(6):777-82.

45. Barbour LA, Pickard J. Controversies in thromboembolic disease during pregnancy: a critical review. Obstet Gynecol. 1995;86(4 Pt 1):621-33.

46. Ginsberg JS, Kowalchuk G, Hirsh J, Brill-Edwards P, Burrows R Heparin therapy during pregnancy. Risks to the fetus and mother. Arch Intern Med.1989;149(10):2233-6. 